\title{
REVSED What role can videogames play in the COVID-19
}

\section{pandemic? [version 2; peer review: 2 approved]}

\author{
Hannah R. Marston (iD), Rachel Kowert² \\ ${ }^{1}$ Health and Wellbeing Strategic Research Area, Open University, UK, Milton Keynes, Buckinghamshire, MK7 6AA, United Kingdom \\ ${ }^{2}$ Take This, Seattle, WA, United States
}

V2 First published: 02 Jun 2020, 2:34
https://doi.org/10.35241/emeraldopenres.13727.1

Latest published: 05 Oct 2020, 2:34

https://doi.org/10.35241/emeraldopenres.13727.2

\section{Abstract}

Video games are often thought of as trite activities for younger generations. However, research in game studies over the last few decades have revealed that games can be valuable tools for growth and connection, particularly among older generations. Exploring the ways digital games can be used as tools for connection has gained increased attention in recent months with global quarantines as a result of COVID-19. This article reviews the research that has examined the utility of digital games for older adults, focusing specifically on the ways in which games can be tools for social connectedness and psychological healing for older adults and intergenerationally. Special focus will be placed on the role games can play for post-traumatic stress among first responders.

\section{Keywords}

Digital games, Social connectedness, Mental health, PTSD, Interaction, Intergenerational, Childless, Ageing

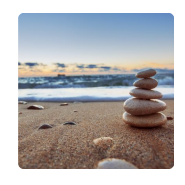

This article is included in the Healthier Lives

gateway.

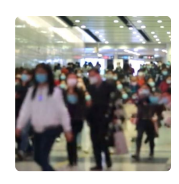

This article is included in the Coronavirus

(COVID-19) collection.

\section{Open Peer Review}

Approval Status

1

2

version 2

(revision)

05 Oct 2020

version 1

02 Jun 2020

$\checkmark$
view
view

$\checkmark$
view
view

1. Dorothy Newbury-Birch, Teesside

University, Middlesbrough, United Kingdom

2. Frans Mäyrä ID, Tampere University,

Tampere, Finland

Any reports and responses or comments on the article can be found at the end of the article. 
Corresponding author: Hannah R. Marston (Hannah.Marston@open.ac.uk)

Author roles: Marston HR: Conceptualization, Methodology, Project Administration, Resources, Supervision, Writing - Original Draft Preparation, Writing - Review \& Editing; Kowert R: Conceptualization, Writing - Original Draft Preparation, Writing - Review \& Editing Competing interests: No competing interests were disclosed.

Grant information: The author(s) declared that no grants were involved in supporting this work.

Copyright: (c) 2020 Marston HR and Kowert R. This is an open access article distributed under the terms of the Creative Commons Attribution License, which permits unrestricted use, distribution, and reproduction in any medium, provided the original work is properly cited.

How to cite this article: Marston HR and Kowert R. What role can videogames play in the COVID-19 pandemic? [version 2; peer review: 2 approved] Emerald Open Research 2020, 2:34 https://doi.org/10.35241/emeraldopenres.13727.2

First published: 02 Jun 2020, 2:34 https://doi.org/10.35241/emeraldopenres.13727.1 


\section{REVISED Amendments from Version 1}

Based on the comments from reviewer 2 we have added

additional information on game playing experience and updated

the references.

Any further responses from the reviewers can be found at the end of the article

\section{Introduction}

Videogames have become a phenomenal form of entertainment over the last 60 years and their history has been documented through various texts (Forster, 2005; Herman, 2001; Kent, 2000). Scholarly activity and research have illustrated this growing interest from academe, with many scholars focusing on the impact, user experience and design of videogame, as illustrated by Marston \& del Carmen (2020) in their recent scoping review that focuses on the Generation $\mathrm{X}$ cohort. This cohort has to date received little attention from academe (Brown \& Marston, 2018), unlike the Baby Boomer cohort, which has received substantial interest from scholars across the fields of gerontology, gerontechnology, media and communications.

One sub-domain of the Game Studies discipline has garnered interest: the Games for Health $(\mathrm{G} 4 \mathrm{H})$ movement. G4H actively facilitates interdisciplinary research in a bid to achieve the primary aims and objectives of this domain, and to date scholarly activity has shown how videogames can be designed, developed and used for a myriad of health conditions. For example, obesity ( $\mathrm{Lu}$ et al., 2013), fall prevention (Marston et al., 2015), dementia (Cutler et al., 2016), and social connectedness (Schell et al., 2016). Since 2010, there has been several scholarly reviews published, with the focus on the benefits of videogames over the last decade (Bleakley et al., 2015; Hall et al., 2012; Marston et al., 2016; Marston \& Smith, 2012; Miller et al., 2014).

The purpose of this opinion piece is to discuss the contemporary landscape of videogames and the relationship that they can and do play from the standpoint of COVID-19.

\section{Intergenerational, social connectedness and loneliness}

From the standpoint of intergenerational gaming (Marston \& Azadvar, 2020), over the last decade there has been a growing interest in videogames from this perspective. Contemporary literature illustrates this growth, with a systematic review published in 2017 (De la Hera et al., 2017), which comprised of 16 papers. This review highlighted four categories: (1) reinforcing family bond, (2) enhancing reciprocal learning, (3) increasing understanding of the other generation, and finally (4) reducing social anxiety. In addition, research conducted by Voida \& Greenberg (2010); Voida \& Greenberg (2009) purport positive design challenges by fostering intergenerational gaming practices. Similarly, De la Hera \& colleagues' (2017) research aligns with the notions of Voida \& Greenberg (2012), and also reason the positive relations between intergenerational gaming and design by understanding the barrier and enablers to existing game console design.
There has been a swathe of contemporary research associated with social connectedness and loneliness by scholars in the field of Gerontology, positing various social factors relating to the experience of social and emotional loneliness, and a disconnect with members of the community and society (Drennan et al., 2008; Heylen, 2010).

de Jong Gierveld (1998) defines loneliness as an unpleasant and negative feeling, especially when there is a perception of disconnection between achieving and desiring the quality and/or quantity of social connections. Additionally, Wenger \& Burholt (2004) have noted that social isolation is an objective measure associated to the dearth of social contact/connections. Markers and experiences in our lives, such as retirement, bereavement, illness, disability or caring responsibilities, can be triggers to loneliness. With this in mind, the COVID-19 pandemic has exacerbated loneliness and social isolation amongst society, not only amongst older populations (Drennan et al., 2008; Ejlskov et al., 2020; Marston \& Morgan, 2020; Yang \& Victor, 2011), but also younger cohorts (Ejlskov et al., 2020), young disabled adults (Morris, 2001), men (Ratcliffe et al. (2019) and childless adults who in/voluntary experience childlessness (Hadley, 2020; Hadley, 2018a; Hadley, 2018b; Hadley, 2019). Hadley (2018b) argues,

"While many age related issues such as isolation, loneliness and dementia have recently gathered extensive attention (and funding) people ageing without children is a subject that remains unreported, under-researched and under-represented at all levels" (Hadley, 2018b, p. 76-77).

Furthermore, a tri-country study (Kendig et al., 2007; Kendig et al., 2010) ascertained associations between childless men and poor health, such as depression, excessive smoking, drinking and difficulty sleeping. Dykstra \& Hagestad (2007) state,

"The childless 'are vulnerable - a group at risk of social isolation, loneliness, depression, ill health and increased mortality"” (Dykstra \& Hagestad, 2007, p. 1288).

In recent weeks, contemporary research posits the potential benefits of technology for all citizens during the COVID-19 pandemic (Marston et al., 2020; Sheerman et al., 2020; White et al., 2020). In addition to existing narratives and discourse, technology is playing a pivotal role in various ecosystems as a means of continuing and enhancing social connections, be it amongst young gamers and/or from an intergenerational standpoint (De la Hera et al., 2017; Marston \& Azadvar, 2020; Voida \& Greenberg, 2010; Voida \& Greenberg, 2009; Wang et al., 2018).

Conversely, does technology and videogames play a greater significant role in the lives of childless middle-and-older adults? To date, there is an absence in the Game Studies, Gerontology and Gerontechnology literature surrounding the benefits and barriers to using technology by adults who are childless.

\section{Health and wellbeing for emergency responders and frontline workers}

There has been growing scholarly activity surrounding the health, wellbeing and post-traumatic stress (PTSD) of emergency 
services personnel (ESP) in the UK. Contemporary research suggests PTSD is greater in ESPs than in the general population (Arble \& Arnetz, 2017; Brooks et al., 2019; Counson et al., 2019; Mildenhall, 2019; Varker et al., 2018).

Currently, research is starting to illustrate and clarify how ESPs are becoming more disproportionately exposed to specific experiences/situations in conjunction to a more overall general working environment. In the context of COVID-19, Mildenhall (2020) offers guidance in the area of psychosocial and mental wellbeing, primarily aimed at paramedics, personnel and managers, while from a policing perspective, Hesketh et al. (2018) offers guidance associated to PTSD, targeting police personnel across the UK.

In a forthcoming scoping review, Marston et al. (2020) demonstrate the paucity in contemporary literature surrounding the design, use and deployment of specific technologies, such as mobile health (mHealth) apps, targeting ESPs, specifically police personnel and support staff. Conversely, the Blue Light Wellbeing Framework (Hesketh \& Williams, 2017) has been designed with the objectives of health and wellbeing provision for both uniformed and support staff. A web portal - Oscar Kilo (OK), deployed for the National Police Wellbeing Service (NPWS) - comprises of a set of independent standards, aimed at police personnel and ESPs, and affords organisations and police forces the opportunity to audit and benchmark themselves against this framework.

The OK framework was co-designed by a myriad of actors (e.g. practitioners (all levels), professionals and academics), and includes five areas: (1) strategic and tactical planning templates, (2) psychological risk management guidance (Hesketh et al., 2017), (3) responding to trauma guidance (Hesketh \& Tehrani, 2019), (4) the GAIN pyramid (Hesketh et al., 2017), and (5) a series of real stories presented in animations. Whilst there is a growing body of evidence, there is still little scholarly evidence to understanding how technologies, such as mHealth apps and/or videogames, can facilitate health, wellbeing and PTSD to front line ESPs and support staff.

The use of videogames to facilitate support and offer treatment for PTSD (Holloway \& Reger, 2013; Macleod \& Sloan, 2017) has garnered greater attention in recent years, with the use of videogames and online virtual environments. While the online virtual environment - Second Life, 2020 (https://secondlife.com/) has previously been used as a tool to offer support to military personnel and their families in an attempt to alleviate PTSD (Hemmerly-Brown, 2019). From a US military personnel perspective, a study by Colder Carras et al. (2018) has been performed, comprising of 20 participants who engaged with videogames as a means of understanding mood and stress levels. Overall, this qualitative study reported positive results by veterans associated with behavioural recovery and PTSD health. The respective authors suggested videogames can act as a form of personal medication, as a way of promoting recovery (Colder et al., 2018, pg. 2). While a systematic review (Callejas-Cuervo et al., 2017) conducted in 2017 and comprising of 15 articles also ascertained positive directions to rehabilitation for PTSD treatment, relating to emotional recognition and videogames.

The videogame Tetris has been used in the environment of an emergency department as an approach of reducing trauma after a traffic accident. Using a randomized control trial (RCT) design, Iyadurai et al. (2018) conducted an intervention that occurred within six hours of the incident. The control group were required to write an activity log for 20 minutes, and the intervention group were required to play Tetris for 20 minutes. Over a period of one week, the aim of the RCT was to compare the number of intrusive trauma memories. Although findings from this proof-of-concept study showed positive benefits at one week, the respective authors suggest a larger and longer trial is needed to understand the benefits at one month.

In the field of game studies scholars have explored game playing experiences (Azadvar \& Dalqvist, 2020; Bianchi-Berthouze et al., 2007; Deterding, 2011; Deterding et al., 2013; De Schutter, 2010; De Schutter \& Brown, 2015; Ermi \& Mäyrä, 2005; Marston, 2013a; Marston et al., 2016; Nacke \& Lindley, 2008; Nacke \& Lindley, 2009; Payne et al., 2011; Voida \& Greenberg, 2012; Whitelock et al., 2014) to understand how players engage with videogames. Generally speaking game playing experiences vary based on the respective game genre(s) been played (De Schutter \& Brown, 2015; Marston, 2013a; Marston et al., 2016; Nacke \& Lindley, 2008; Nacke \& Lindley, 2009; Voida \& Greenberg, 2012; Whitelock et al., 2014). For example, players may experience deep meaningful game experiences through role-playing games, whereas simulation or puzzle games may not elicit the same experience (Connell \& Dunlap, 2020). It is also important to understand the role of player motivations on game experience. If a player is highly motivated to achieve, then Incorporating gamification elements that provide feedback on progress, such as goals rewards and leader boards, could influence their gaming experience exponentially (Deterding, 2011; Deterding et al., 2011; Deterding et al., 2011; Havukainen et al., 2020; Marston \& Hall, 2015). Understanding the purpose or motivations of a gamer can afford the game design to be tailored specifically, especially if you are planning to design a game aimed at a specific audience (De Schutter, 2010; Marston, 2013b; Marston et al., 2015; Pearce, 2008) or rationale. Therefore, understanding the motivations of the target audience is important for game design (Apperley, 2006; De Schutter, 2010; Elliott et al., 2012; Goddard \& Muscat, 2017; Havukainen et al., 2020; Marston, 2013b) and potential positive outcomes via gameplay.

\section{Gaming in a time of COVID-19}

Videogames have become a feature in the homes of many citizens old and young over the last several decades, transforming the home to one which now accepts the videogame console as a feature. Flynn (2003) describes the domestication of the home and states,

"The home is once again framed as 'a machine for living in' with the user most 'at home' when playing the game console" (Flynn, 2003, pg. 558). 
The history of videogames is long documented (Forster 2005; Herman, 2001; Kent, 2000), detailing the move of videogames from public space into private - the home. Flynn (2003) purports how the videogame consoles over the decades has been implemented into the living space - of the digital hearth to feature and sit alongside the additional pieces of furniture in this physical space. At the time of writing this specific piece $\left(21^{\text {st }}\right.$ Century), Flynn pontificates and narrates the perceptions and portrayals of digital consumption 100 years earlier, describing the difference between a country house environment and prospective future housing environmental design. Whereby over the decades, one's lifestyle, gender and media influences has led to redefining how key pieces of technology are represented and identified specifically by women (Massey, 2000). For example,

"From this examination of the contemporary ideal home, it would appear that for the middle-class female readership of lifestyle magazines, the video console is still an alien machine in relation to narratives of identity associated with domesticity and family togetherness." (Flynn, 2003, pg. 565).

The notion of videogames portrayed in magazines illustrated the alternative physical space or third place (e.g. the bedroom) to game playing, rather than the living room or the digital hearth as previously described by Flynn (2003). Whereas, the previous notion of the living room as the familial space - or the suburban living room - as the gaming/meeting place was been replaced by such advertisements purported by games industry companies (McGuire, 2003).

Existing research (De la Hera et al., 2017; Voida \& Greenberg, 2010; Voida \& Greenberg, 2009; Wang et al., 2018) and the work presented by Flynn (2003), illustrates how videogames can enhance interaction within the physical space(s) with other gamers, and adults alike. During this unprecedented time in society, COVID-19 is impacting many physical spaces and ecosystems (Marston et al., 2020; Sheerman et al., 2020; White et al., 2020), be it a community group, a family, middleaged or older adults living on their own, or a keyworker. Yet, videogames and their peripheral technologies can and do have a role to play in continuing and enhancing social connections, relationships and engagements, from within the ecosystem and/or across WiFi communications.

It is important to note the unique contribution that games provide to mediated socialization. The fact that games are playful, fun, interactive spaces differentiates them from other forms of mediated communication, such as text messaging or social media (Kowert, 2015). They allow individuals to connect through play, which is an important facet of psychological well-being throughout the lifespan (Connell \& Dunlap, 2020). Play in and of itself is associated with reduced stress and depression, as well as a releasing of endorphins (Robinson et al., 2019). Combined with the various benefits of in-game socialization (i.e., reduced stress, depression, and sense of loneliness; see Kowert, 2015) makes games a useful tool for mitigating some of the negative impacts of COVID-19 for adults.
Taking a different route in this discussion and turning our attention to the growth of evidence positively supporting and facilitating health, wellbeing and PTSD in different populations, in addition to enhancing intergenerational relationships, further considerations are needed. For example, in this opinion piece, we have explored contemporary literature surrounding intergenerational gaming. However, for those citizens who are ageing without children or grandchildren, how can videogames facilitate positive health and wellbeing, social connections and reduce a sense of loneliness? We suggest here that future research should explore how videogames are used as a means of understanding social connections and reducing loneliness by middle-age and older adults. As previously noted by Hadley (2018b), scholarly research is underrepresented in the field of people ageing without children. Given the situation(s) that this pandemic has placed on citizens, for those who perceive themselves as gamers, and who may not have children or grandchildren, they may have already chosen to use videogames as a means of socially connecting with friends in an online environment. Using videogames as a means of socially connecting with un/known gamers may afford a person a sense of positive feeling.

From the standpoint of ESPs, evidence is growing that illustrates the need for identifying appropriate solutions for treatment of PTSD and for continuing positive health and wellbeing practices within the workforce. As noted in their forthcoming review, Marston et al. (2020) purport the paucity of existing literature surrounding technology use and deployment for ESPs in association with health, wellbeing and PTSD. Furthermore, they provide a series of recommendations in an attempt to move this interdisciplinary work forward, and given the current situation within society (associated to COVID-19), there is the likelihood that health practitioners, and social care keyworkers may require health, wellbeing and PTSD rehabilitation/recovering in the future. For instance, keyworkers such as those who are working in our hospitals are witnessing multiple deaths throughout their shifts, and days, and in some instance of their colleagues. Furthermore, deaths of citizens are also been reported from care/nursing homes, and many health and social care workers have chosen to 'live in' and shield the residents from COVID-19.

\section{Conclusions}

In this opinion piece, we have demonstrated how videogames can play a pivotal role in various societal ecosystems from the individual/digital hearth to the larger ecosystem surrounding ESPs, health practitioners, and social care workers, who at present are exposed to various situations and trauma.

Moving this debate forward, interdisciplinary research is needed to focus on two landscapes. Firstly, from the standpoint of social sciences and how videogames can impact the lives of middle-and-older adults who are ageing without children. As previously noted, there is a paucity of research specifically focusing on adults who are ageing without children. Social connectedness and loneliness are key experiences, and more information and understanding are required to offer solutions to reduce these risks. 
Secondly, more research is required from the standpoint of videogames and ESPs and the role in which videogames can be a means of reducing trauma, offering positive health, wellbeing and PTSD solutions. This would require efforts from a myriad of actors, forming a co-designed and co-produced approach to ensure all key information and take-up is included.

\section{Data availability}

No data is associated with this article.
Apperley T: Genre and game studies: Towards a critical approach to video game genres. Simulation \& Gaming: an International Journal of Theory Practice and Research. 2006; 37: 1; 6-23.

Publisher Full Text

Arble E, Arnetz BB: A Model of First-responder Coping: An Approach Avoidance Bifurcation. Stress Health. 2017: 33(3): 223-232.

PubMed Abstract | Publisher Full Text | Free Full Text

Azadvar A, Dalqvist E: Aging Agents: Cross Generational Analysis of Behavior and Need Satisfaction Among Players of Tom Clancy's The Division 2. Comput Game I. 2020: 9:245-262.

Publisher Full Text

Bianchi-Berthouze N, Kim WW, Patel DI: Does body movement engage you more in digital game play? And why? In A. Paiva, R. Prada, \& R. W. Picard (Eds.), Affective Computing and Intelligent Interaction Second International Conference. (ACII 2007). New York, NY: Springer. 2007; 102-113. Publisher Full Text

Bleakley CM, Charles D, Porter-Armstrong A, et al:: Gaming for Health: A Systematic Review of the Physical and Cognitive Effects of Interactive Computer Games in Older Adults. J Appl Gerontol. 2015; 34(3): NP166-NP189. PubMed Abstract | Publisher Full Text

Brooks SK, Dunn R, Amlôt R, et al.: Protecting the psychological wellbeing of staff exposed to disaster or emergency at work: a qualitative study. $B M C$ Psychol. 2019; 7(1): 78.

PubMed Abstract | Publisher Full Text | Free Full Text

Brown JA, Marston HR: Gen X and Digital Games: Looking Back to Look Forward. In: Zhou J., Salvendy G. (eds) Human Aspects of IT for the Aged Population. Applications in Health, Assistance, and Entertainment. ITAP 2018. Lecture Notes in Computer Science, vol 10927. Springer, Cham. 2018. Publisher Full Text

Callejas-Cuervo M, Martínez-Tejada L, Alarcón-Aldana A: Emotion recognition techniques using physiological signals and video games -Systematic review-. Revista Facultad De Ingeniería. 2017; 26(46): 19-28.

Publisher Full Text

Colder Carras M, Kalbarczyk A, Wells K, et al.: Connection, Meaning, and Distraction: A Qualitative Study of Video Game Play and Mental Health Recovery in Veterans Treated for Mental and/or Behavioral Health Problems. Soc Sci Med. 2018; 216: 124-132.

PubMed Abstract | Publisher Full Text | Free Full Text

Connell M, Dunlap K: You are the one foretold; Finding yourself through the journey. In R. Kowert (Ed.) Video Games and Well-Being. New York: Palgrave. 2020; $125-140$.

Publisher Full Text

Counson I, Hosemans D, Lal TJ, et al.: Mental health and mindfulness amongst Australian fire fighters. BMC Psychol. 2019; 7(1): 34

PubMed Abstract | Publisher Full Text | Free Full Tex

Cutler C, Hicks B, Innes A: Does Digital Gaming Enable Healthy Aging for Community-Dwelling People With Dementia? Games Cult. 2016; 11(1-2): 104-129.

Publisher Full Text

de Jong Gierveld J: A review of loneliness: concept and definitions, determinants and consequences. Rev Clin Gerontol. 1998; 8(1): 73-80. Publisher Full Text

De la Hera T, Loos E, Simons M, et al.: Benefits and factors influencing the design of intergenerational digital games: A systematic literature review. Societies. 2017; 7(3): 18

Publisher Full Text

De Schutter B: Never Too Old to Play: The Appeal of Digital Games to an Older Audience. Games \& Culture. 2010; 6(2): 155-170.

Publisher Full Text

De Schutter B, Brown JA: Digital Games as a Source of Enjoyment in Later Life. Games and Culture: A Journal of Interactive Media. 2015; 11(1-2): 28-52. Publisher Full Text

Deterding $D$, Dixon $D$, Khaled $R$, et al.: From game design elements to gamefulness: defining "gamification". In Proceedings of the 15th International Academic MindTrek Conference: Envisioning Future Media Environments (MindTrek 11). Association for Computing Machinery, New York, NY USA, 2011; 9-15. Publisher Full Text

Deterding S: Meaningful play: Getting gamification right. Google Tech Talk. 2011; 24: 2011.

Reference Source

Deterding S, Björk SI, Nacke LE, et al.: Designing gamification: creating gameful and playful experiences. In CHI '13 Extended Abstracts on Human Factors in Computing Systems (CHI EA '13). Association for Computing Machinery, New York, NY USA, 2013; 3263-3266.

Publisher Full Text

Deterding $S$, Khaled R, Nacke LE, et al.: Gamification: Toward a definition. In CHI 2011 gamification workshop proceedings. Vancouver BC Canada. 2011; 12. Reference Source

Drennan J, Treacy M, Butler M, et al.: The experience of social and emotional Ioneliness among older people in Ireland. Ageing Soc. 2008; 28(8): 1113-1132. Publisher Full Text

Dykstra PA, Hagestad GO: Childlessness and Parenthood in Two Centuries: Different Roads-Different Maps? J Fam Issues. 2007; 28(11): 1518-1532. Publisher Full Text

Elliott L, Ream G, McGinsky E, et al.: The Contribution of Game Genre and other Use Patterns to Problem Video Game Play among Adult Video Gamers. Int J Ment Health Addict. 2012; 10(6): 948-969.

PubMed Abstract | Publisher Full Text | Free Full Text

Ejlskov L, Bøggild H, Kuh D, et al.: Social relationship adversities throughout the lifecourse and risk of loneliness in later life. Ageing Soc. 2020; 40(8): 1718-1734.

Publisher Full Text

Ermi L, Mäyrä F: Fundamental components of the gameplay experience: Analysing immersion. DiGRA conference Changing views: Worlds in play, Vancouver, Canada. 2005.

Reference Source

Flynn B: Geography of the Digital Hearth. Information, Communication \& Society. 2003; 6(4): 551-576.

Publisher Full Text

Forster W: The Encyclopedia of game machines-Consoles, handheld and home computers 1972-2005. Boca Raton: Game Plan. 2005. Reference Source

Goddard W, Muscat A: Towards Genre as a Game Design Research Approach Proceedings of DiGRA 2017. 2017.

Reference Source

Hadley RA: Men and me(n). Methodological Innovations. 2020; 13(2). Publisher Full Text

Hadley RA: The lived experience of older involuntary childless men. The Annual Journal of the British Sociological Association Study Group on Auto/ Biography 2018a; 2017: 93-108.

Reference Source

Hadley RA: Ageing Without Children, gender and social justice. In Westwood, S. (ed.), Ageing, Diversity and Equality: Social justice perspectives, Routledge: Abingdon. 2018b; 66-81.

Reference Source

Hadley RA: Deconstructing Dad. In John Barry, Roger Kingerlee, Martin Seager and Luke Sullivan (eds.), The Palgrave Handbook of Male Psychology and Mental Health. Palgrave Macmillan: London. 2019; 47-66.

Publisher Full Text

Havukainen M, Laine TH, Martikainen T, et al.: A Case Study on Co-designing Digital Games with Older Adults and Children: Game Elements, Assets, and Challenges. Comput Game. 2020; 9: 163-188.

Publisher Full Text

Hall AK, Chavarria E, Maneeratana V, et al.: Health benefits of digital videogames for older adults: A systematic review of the literature. Games 
Health J. 2012; 1(6): 402-410.

PubMed Abstract | Publisher Full Text

Hemmerly-Brown A: DoD gives PTSD help 'second life' in virtual reality. U.S. Army. 2019; Accessed 19th May 2020

Reference Source

Herman L: Phoenix: The fall and rise of videogames. 2001; Springfield:

Rolenta Press.

Reference Source

Hesketh I, Williams S: Blue Light Wellbeing Framework. College of Policing London, 2017.

Reference Source

Hesketh I, Tehrani N: Psychological Trauma Risk Management in the UK Police Service. Policing: A Journal of Policy and Practice. 2019; 13(4): 531-535. Publisher Full Text

Hesketh I, Tehrani N, Harrison J: Psychological Risk Management: Introduction \& Guidance. College of Policing Ltd. 2017; Accessed $7^{\text {th }}$ April 2020.

Reference Source

Hesketh I, Tehrani N, Harrison J, et al.: Post-Traumatic Stress Disorder (PTSD) and Policing - Short Guidance Document. College of Policing Ltd. 2018. Reference Source

Heylen L: The older, the lonelier? Risk factors for social loneliness in old age. Ageing Soc. 2010; 30(7): 1177-1196.

Publisher Full Text

Holloway KM, Reger GM: T2 Virtual PTSD Experience: A Virtual Worlds

Environment to Educate Service Members and Veterans About Combat-

Related Posttraumatic Stress Disorder. Int J Hum Comput Interact. 2013; 29(9):

594-603.

Publisher Full Text

Iyadurai L, Blackwell SE, Meiser-Stedman $\mathrm{R}$, et al: Preventing intrusive memories after trauma via a brief intervention involving Tetris compute game play in the emergency department: a proof-of-concept randomized controlled trial. Mol Psychiatry. 2018; 23(3): 674-682.

PubMed Abstract | Publisher Full Text | Free Full Text

Kendig $\mathrm{H}$, Browning $\mathrm{C}$, Pedlow $\mathrm{R}$, et al.: Health, social and lifestyle factors in entry to residential aged care: an Australian longitudinal analysis $\mathrm{Age}$ Ageing. 2010; 39(3): 342-349.

PubMed Abstract | Publisher Full Text

Kendig $\mathrm{H}$, Dykstra PA, van Gaalen RI, et al: Health of Aging Parents and

Childless Individuals. J Fam Issues. 2007; 28(11): 1457-1486.

Publisher Full Text

Kent SL: The first quarter: A 25-year history of video games. Pitampura: BWD Press. 2000.

Reference Source

Kowert R: Video Games and Social Competence. New York: Routledge. 2015. Publisher Full Text

Lu AS, Kharrazi H, Gharghabi F, et al.: A Systematic Review of Health Videogames on Childhood Obesity Prevention and Intervention. Games Health J. 2013; 2(3): 131-141.

PubMed Abstract | Publisher Full Text | Free Full Text

Macleod E, Sloan R: Recover: designing a videogame to assist with recovery from PTSD. Paper presented at The ACM SIGCHI Annual Symposium on ComputerHuman Interaction in Play. Amsterdam, Netherlands. 2017.

Reference Source

Marston HR: Digital Gaming Perspectives of Older Adults: Content vs Interaction. Educational Gerontology. 2013a; 39(3): 194-208. Publisher Full Text

Marston HR: Design recommendations for digital game design within an ageing society. Educational Gerontology. 2013b; 39(2): 103-118.

Publisher Full Text

Marston HR, Azadvar A: Defeating the Boss Level ... Exploring Inter-andMultigenerational Gaming Experiences. Comput Game J. 2020; 9: 121-126. Publisher Full Text

Marston HR, Hadley R, Pike G, et al.: Games for health \& mHealth apps for police \& blue light personnel: A research review. The Police Journal. 2020. Publisher Full Text

Marston HR, Hall AK: Gamification: Application for Health and Health Information Technology Engagement. In D. Novak, B. Tulu, \& H. Brendryen (Eds.) Handbook of Research on Holistic Perspectives in Gamification for Clinical Practice. Hershey, PA: Medical Information Science Reference. 2015; 78-104. Publisher Full Text

Marston $\mathrm{HR}$, Kroll M, Fink $\mathrm{D}$, et al.: Flow experience of older adults using the iStoppFalls exergames. Special Issue: Gaming \& Aging: Games \& Culture Journal. 2016: 11(1-2): 201-222.

Publisher Full Text

Marston HR, del Carmen Miranda Duro M: Revisiting the Twentieth Century Through the Lens of Generation X and Digital Games: A Scoping Review. Comput Game J. 2020; 9: 127-161.

Publisher Full Text

Marston HR, Freeman S, Bishop A, et al.: Utilization of digital games for older adults aged 85+ years: A scoping review. Games for Health Journal. 2016; 5(3):
157-174

Publisher Full Tex

Marston HR, Morgan DJ: Technology \& Social Media during CoVID-19 Pandemic. Special Issue: COVID-19 \& Geriatric Mental Health Worldwide. IPA Bulletin. 2020

Reference Source

Marston HR, Musselwhite C, Hadley RA: CovID-19 vs Social Isolation: the impact technology can have on communities, social connections and citizens. Ageing Issues. 2020

Reference Source

Marston HR, Smith ST: Interactive videogame technologies to support independence in the elderly: A narrative review. Games Health J. 2012; 1(2): 139-152.

PubMed Abstract | Publisher Full Tex

Marston HR, Woodbury A, Kroll M, et al.: The design of a purpose built Exergame for fall prediction and prevention amongst older adults. European Review of Aging and Physical Activity (EURAPA). 2015; 12: 13. PubMed Abstract | Publisher Full Text | Free Full Text

Massey D: Space, Place and Gender. Minneapolis, MN: University of Minnesota Press. 2000.

Reference Source

McGuire M: Playstation 2: Selling the Third Place, DAC conference proceedings. Melbourne: RMIT University. 2003.

Mildenhall J: Guidance for managers on psychosocial support and mental wellbeing of ambulance personnel in a pandemic crisis. College of Paramedics. 2020; Accessed $07^{\text {th }}$ April 2020.

Reference Source

Mildenhall J: Protecting the mental health of UK paramedics. Journal of Paramedic Practice. 2019; 11(1): 6-7.

Publisher Full Text

Miller KJ, Adair BS, Pearce Al, et al: Effectiveness and Feasibility of Virtual Reality and Gaming System Use at Home by Older Adults for Enabling Physical Activity to Improve Health-Related Domains: A Systematic Review. Age Ageing. 2014; 43(2): 188-195.

PubMed Abstract | Publisher Full Tex

Morris !: Social exclusion and young disabled people with high levels of support needs. Crit Soc Policy. 2001; 21(2): 161-183.

Publisher Full Text

Nacke L, Lindley C: Flow and immersion in first-person shooters: Measuring the player's gameplay experience. In: Proceeding of the 2008 conference on future play: Research, play, share. Toronto, Canada: ACM. 2008; 87-88.

Reference Source

Nacke L, Lindley C: Affective ludology, flow and immersion in a first-person shoot: Measurement of player experience. Loading, 3. 2009.

Reference Source

Payne BR, Jackson JJ, Noh SR, et al.: In the zone: Flow state and cognition in older adults. Psychol Aging. 2011; 26(3): 738-743.

PubMed Abstract | Publisher Full Text | Free Full Text

Pearce C: The Truth About Baby Boomer Gamers: A Study of Over-Forty Computer Game Players. Games and Culture. 2008; 3(2): 142-174.

Publisher Full Text

Ratcliffe J, Wigfield A, Alden S: ‘A lonely old man': Empirical investigations of older men and loneliness, and the ramifications for policy and practice. Ageing Soc. 2019; 1-21.

Publisher Full Text

Robinson L, Smith M, Segal J, et al.: The Benefits of Play for Adults. 2019; Retrieved.

Reference Source

Schell R, Hausknecht S, Zhang F, et al:: Social Benefits of Playing Wii Bowling

for Older Adults. Games and Culture. 2016: 11(1-2): 81-103.

Publisher Full Text

Second Life: Linden Research, Inc. 2020; Accessed 19th May 2020.

Reference Source

Sheerman L, Marston HR, Musselwhite C, et al.: COVID-19 and the secret virtual assistants: the social weapons for a state of emergency [version 1 ; peer review: awaiting peer review]. Emerald Open Res. 2020; 2: 19.

Publisher Full Text

Varker T, Metcalf O, Forbes D, et al.: Research Into Australian Emergency Services Personnel Mental Health and Wellbeing: An Evidence Map. Aust $N$ ZJ Psychiatry. 2018; 52(2): 129-148.

PubMed Abstract | Publisher Full Text

Voida A, Greenberg S: Wii all play: The console game as a computational meeting place. In: Proceedings of the 27th international conference on human factors in computing systems-CHI'09. 2009; 1559-1568.

Publisher Full Text

Voida A, Greenberg S: A gameroom of our own: Exploring the domestic gaming environment. Alberta: Calgary. 2010.

Publisher Full Text

Voida A, Greenberg S: Console gaming across generations: Exploring intergenerational interactions in collocated console gaming. Univers Access 
Inf Soc. 2012; 11(1): 45-56.

Publisher Full Text

Wang B, Taylor L, Sun Q: Families that play together stay together:

Investigating family bonding through video games. New Media and Society. 2018; 20(11): 4074-4094.

Publisher Full Text

Wenger GC, Burholt V: Changes in levels of social isolation and loneliness among older people in a rural area: a twenty-year longitudinal study. Can J

Aging. 2004; 23(2): 115-127.

PubMed Abstract | Publisher Full Text

White PJ, Marston HR, Shore L, et al.: Learning from COVID-19: Design,
Age-friendly Technology, Hacking and Mental Models [version 1; peer review: awaiting peer review]. Emerald Open Res. 2020; 2: 21.

Publisher Full Text

Whitelock LA, McLaughlin AC, Leidheiser W, et al:: Know before you go: feelings of flow for older players depends on game and player characteristics. In: Proceedings of the first ACM SIGCHI annual symposium on Computer human interaction in play. 2014; 277-286.

Publisher Full Text

Yang K, Victor C: Age and loneliness in 25 European nations. Ageing and Society. 2011; 31(8): 1368-1388.

Publisher Full Text 


\section{Open Peer Review}

\section{Current Peer Review Status:}

\section{Version 2}

Reviewer Report 06 October 2020

https://doi.org/10.21956/emeraldopenres.15039.r27155

(C) 2020 Newbury-Birch D. This is an open access peer review report distributed under the terms of the Creative Commons Attribution License, which permits unrestricted use, distribution, and reproduction in any medium, provided the original work is properly cited.

\section{Dorothy Newbury-Birch}

School of Social Sciences Humanities and Law, Teesside University, Middlesbrough, United Kingdom

No further comments.

Competing Interests: No competing interests were disclosed.

Reviewer Expertise: Public Health

I confirm that I have read this submission and believe that I have an appropriate level of expertise to confirm that it is of an acceptable scientific standard.

Reviewer Report 05 October 2020

https://doi.org/10.21956/emeraldopenres.15039.r27154

(C) 2020 Mäyrä F. This is an open access peer review report distributed under the terms of the Creative Commons Attribution License, which permits unrestricted use, distribution, and reproduction in any medium, provided the original work is properly cited.

\section{Frans Mäyrä}

Faculty of Information Technology and Communication Sciences, Tampere University, Tampere, Finland

I appreciate the effort to add more details on game playing experiences research.

Competing Interests: No competing interests were disclosed.

Reviewer Expertise: Game studies, game culture studies, humanities, art and culture studies. 


\section{I confirm that I have read this submission and believe that I have an appropriate level of expertise to confirm that it is of an acceptable scientific standard.}

\section{Version 1}

Reviewer Report 26 August 2020

https://doi.org/10.21956/emeraldopenres.14802.r27060

(C) 2020 Mäyrä F. This is an open access peer review report distributed under the terms of the Creative Commons Attribution License, which permits unrestricted use, distribution, and reproduction in any medium, provided the original work is properly cited.

\section{Frans Mäyrä}

Faculty of Information Technology and Communication Sciences, Tampere University, Tampere, Finland

This is an interesting and well-studied article that brings together a lot of research from game studies and the games-for-health field in particular. It is good to note that health and well-being is here approached from a wide-ranging and inclusive perspective, taking sociocultural aspects of health also into consideration. The role of loneliness and social connectedness is particularly emphasised, which is a relevant choice, considering the role of games and play as particular kinds of popular social activities. There is also a topical framing of this article in the recent COVID-19 pandemic and its associated risks for social isolation and loneliness.

The main body of research literature and discussion in this short article is directed towards addressing games' potential for positively supporting health, particularly in the case of PTSD (posttraumatic stress disorder). The suggestion of authors is that under the pandemic, health workers would particularly benefit from the use of games for recovery. This seems plausible, and also supported by literature (though, it should be noted that I am not an expert in health or therapies). What might be missing, or not given similar kind of treatment, is the games' relationship to the socially isolating and stressful conditions in everyday lives of "non-professionals" (i.e. in lives of families, students, and many other people). But, as said, this is a short article and a certain focus is a good thing.

From a game studies perspective, it should also be noted that there is not much discussion about the differences between different genres or forms of games and play that actually vary a lot. Games are discussed in very overarching and generalising terms. There are also significant differences in players' responses of games, and while one kind of game might be relaxing and therapeutic for some, it might be frustrating and anxiety creating for someone else. Such, more fine-grained discussions that are relevant to game studies have fallen outside of the scope of this short article, but it would be welcome to see at least some short references into such directions.

The article is logically structured and generally well-written, but there were some instances of word choices and sentence structures that left me wishing for yet one more round of minor 
stylistic proof-reading. Maybe such small amendments could still be made into the text? Otherwise I think that this article is solid work, puts forward a valuable perspective and contribution, and should indeed be indexed.

Is the topic of the opinion article discussed accurately in the context of the current literature?

Yes

Are all factual statements correct and adequately supported by citations? Yes

Are arguments sufficiently supported by evidence from the published literature? Yes

Are the conclusions drawn balanced and justified on the basis of the presented arguments? Yes

Is the argument information presented in such a way that it can be understood by a nonacademic audience?

Yes

Does the piece present solutions to actual real world challenges?

Yes

Is real-world evidence provided to support any conclusions made? Yes

Could any solutions being offered be effectively implemented in practice? Yes

Competing Interests: No competing interests were disclosed.

Reviewer Expertise: Game studies, game culture studies, humanities, art and culture studies.

I confirm that I have read this submission and believe that I have an appropriate level of expertise to confirm that it is of an acceptable scientific standard.

Reviewer Report 16 July 2020

https://doi.org/10.21956/emeraldopenres.14802.r26958

(C) 2020 Newbury-Birch D. This is an open access peer review report distributed under the terms of the Creative Commons Attribution License, which permits unrestricted use, distribution, and reproduction in any medium, provided the original work is properly cited.

Dorothy Newbury-Birch 
School of Social Sciences Humanities and Law, Teesside University, Middlesbrough, United Kingdom

This is a very good piece of work that is worthy of publication. I only have a couple of small things to consider:

On page 3 when talking about COVID-19 I suggest that papers relating to COVID-19 are referenced separately to other data that says the same thing.

I think there should be some mention of testing through proper RCTS the effectiveness and costeffectiveness of interventions. The Lyadurai et al study had a one week follow up and the paper indicates that it would be better at a month however that is not a long enough time to really consider whether it is effective.

Well done to the authors - this is a well written article.

Is the topic of the opinion article discussed accurately in the context of the current literature?

Yes

Are all factual statements correct and adequately supported by citations? Yes

Are arguments sufficiently supported by evidence from the published literature? Yes

Are the conclusions drawn balanced and justified on the basis of the presented arguments? Yes

Is the argument information presented in such a way that it can be understood by a nonacademic audience?

Yes

Does the piece present solutions to actual real world challenges?

Yes

Is real-world evidence provided to support any conclusions made?

Yes

Could any solutions being offered be effectively implemented in practice?

Yes

Competing Interests: No competing interests were disclosed.

Reviewer Expertise: Public Health

I confirm that I have read this submission and believe that I have an appropriate level of 
expertise to confirm that it is of an acceptable scientific standard. 